\title{
Bibliometric Analysis of the Field of Professional Ethics Education
}

\author{
Zhangsheng Liu*, Wenhui Wang \\ College of City Construction, Jiangxi Normal University, Nanchang, China \\ Email: ^liuzs8033@hust.edu.cn
}

How to cite this paper: Liu, Z. S., \& Wang, W. H. (2019). Bibliometric Analysis of the Field of Professional Ethics Education. Chinese Studies, 8, 194-209.

https://doi.org/10.4236/chnstd.2019.84016

Received: October 8, 2019

Accepted: November 26, 2019

Published: November 29, 2019

Copyright $\odot 2019$ by author(s) and Scientific Research Publishing Inc. This work is licensed under the Creative Commons Attribution International License (CC BY 4.0).

http://creativecommons.org/licenses/by/4.0/

\begin{abstract}
Professional ethics education is an indispensable part of vocational education. Integrating the cultivation and practice of socialist core values into professional ethics education pointed out in the report of the 19th National Congress is an inherent requirement for practicing socialist values. With the help of the visual knowledge mapping tool Citespace software, the papers of the core journals with the theme of "Ideological and Political Education" in the CNKI database since 1993 are studied. The current situation of research in this field is revealed by the statistics of the amount of papers, the co-occurrence analysis of research institutions and research authors. The main content of research in this field is clarified by the analysis of highly cited papers. Through the analysis of keyword co-occurrence, this paper reveals the hot issues in this field, and through the analysis of the time zone distribution of keywords, clarifies the development context of this field to accurately grasp the research process in the field of professional ethics education in China. In order to further strengthen the study of professional ethics education in China, it provides reference, and then improves the effect of professional ethics education.
\end{abstract}

\section{Keywords}

Professional Ethics Education, Citespace, Professional Ethics

\section{Introduction}

The report of the 17th National Congress of the Communist Party of China pointed out that to promote the great development and prosperity of socialist culture, it is necessary to "strengthen social morality, professional ethics, family virtues and personal morality, and guide people to consciously perform their legal obligations, social responsibilities and family responsibilities.” Wu \& Liu 
(2017) pointed out that vocational moral education is not only an important part of the current moral education in Colleges and universities, but also an important part of quality education. It is also the basis of Vocational College Students' view of career selection and even the formation of values education. The core goal of professional ethics education is to pursue the effectiveness of educational results (Wang, 2017). However, the formation of professional ethics is affected by many social factors. As the degree of professional education of practitioners is getting higher and higher, the professional ethics education of colleges and universities has not followed up (Xiao \& Zhu, 2004), which leads to a variety of social evaluations of the professional ethics of employees in different industries. There are many evaluations of professional ethics, and at the same time, it has also led to a large number of scholars' in-depth discussion of professional ethics education.

Although the amount of literature on professional ethics education has reached a certain number, few scholars have introduced and combed existing achievements in the past relevant research results, and the quantitative analysis of professional ethics education by using the bibliometric method is one of the few. Based on this, this paper uses the papers included in the core journals of China Knowledge Network (CNKI) as the data source, and sets the subject word as "professional moral education". The search is completed as of 2018, and a total of 1103 records are obtained. Unrelated papers such as notices, journal catalogues, and news reports, and finally 596 sample articles were obtained. Then, we use Excel, Citespace and other software to visualize the literature. Among them, Excel carries out traditional data statistics and analysis, Citespace realizes co-existing map analysis of authors and institutions, and co-occurrence and timely analysis of keywords. Finally, the hot issues and future trends in the field of professional ethics education are obtained in order to provide systematic and relevant guidance for the research in this field.

\section{Analysis of Research Status}

\subsection{Literature Quantity}

Through the analysis of the amount of papers in different years, the research progress in the field of professional ethics education can be predicted. Figure 1 shows the year distribution of the papers on professional ethics education in core journals from 1993 to 2018. From the time point of view, scholars' research on professional ethics education was in its infancy in 1993-2003, and slowly grew to 16 articles in 2003. In 2006, the Central Committee of the Communist Party of China and the State Council, from the "Decision on Deepening Education Reform and Promoting Quality Education in an All-round Way" to the "Outline of the National Medium-and Long-term Talent Development Plan (2010-2020)", took vocational quality as an important requirement for talents adapting to the new industrialization and the optimization and upgrading of industrial structure (Sun, 2012). At the same time, although the number of related documents in this 


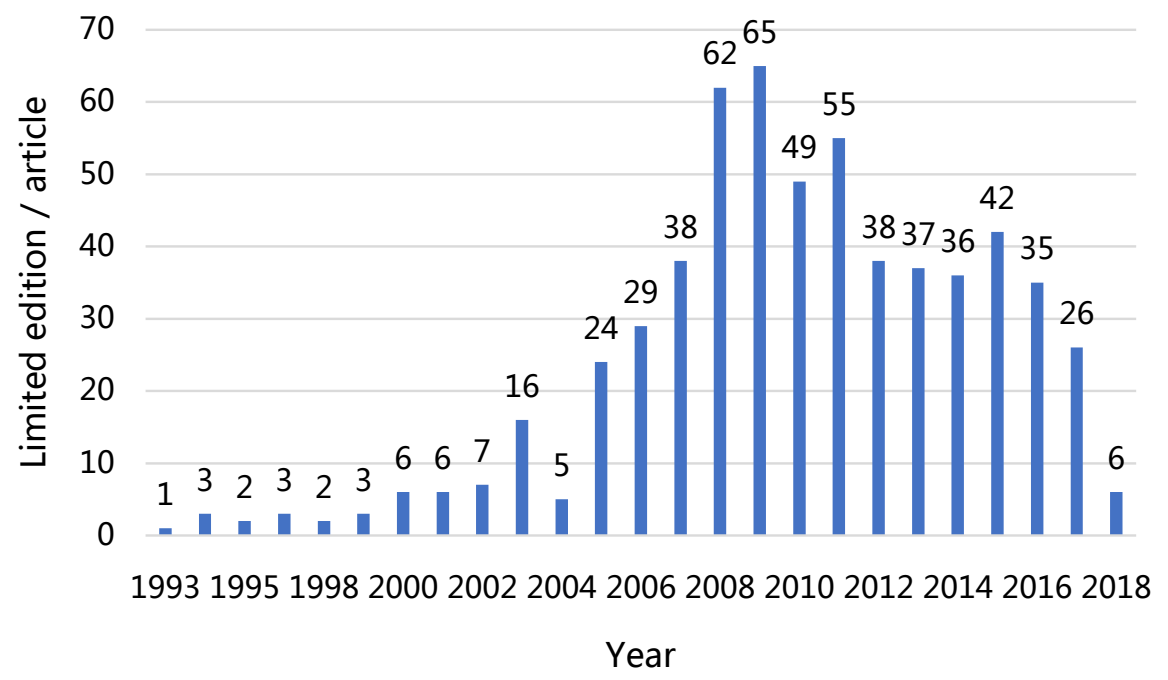

Figure 1. Trends in the literature on professional ethics education.

period of 2004-2009 was low in 2004, it generally showed a rapid growth during this period and reached its peak in 2009, indicating that scholars' attention to professional ethics education was significantly improved at this stage. The number of related documents in 2010-2018 shows a trend of slow decline, with only 6 articles in 2018. Based on the development law of the literature and the development needs of human civilization, it can be predicted that the research on this topic will continue.

\subsection{Distribution of Literature Periodicals}

Table 1 lists more than ten journals with a total of 322 articles on professional ethics education, accounting for $54.03 \%$ of the sample literature. It can be seen from Table 1 that the high-ranking journals in this field are mainly distributed in occupations, education, etc. Among them, the most published articles are Education and Vocation, followed by Chinese Vocational and Technical Education, Journal of Vocational Education, China Adult Education and so on. The literature published in these journals covers many aspects of research in this field, and it also represents a research hotspot in this research field to a certain extent, and follow-up scholars can use it as a reference source for journals.

\subsection{Research Institution Analysis}

First of all, in the sample literature, the information of the research institutions with more than three publications is shown in Table 2. Among them, Public Management Department of Liuzhou Teachers College is ranked first and it has 6 articles. Secondly, the number of documents issued is Zhejiang Financial College and Institute of Vocational Education and Adult Education, East China Normal University.

Then, in order to more comprehensively analyze the situation of research institutions in this field, this paper uses Citespace software to generate the research 
Table 1. Journal statistics table with $\geq 10$.

\begin{tabular}{ccc}
\hline Periodical & Number of articles/articles & Proportion/\% \\
\hline Education and Vocation & 98 & 16.44 \\
Chinese Vocational and Technical Education & 55 & 9.23 \\
Journal of Vocational Education & 50 & 8.39 \\
China Adult Education & 49 & 8.22 \\
Vocational and Technical Education & 27 & 4.53 \\
The Party Building and Ideological Education in Schools & 22 & 3.69 \\
Education Exploration & 11 & 1.85 \\
Adult Education & 10 & 1.68 \\
\hline
\end{tabular}

Table 2. Research institution information table with the number of documents $\geq 3$.

\begin{tabular}{lcc}
\hline \multicolumn{1}{c}{ Institution } & Issue volume & area \\
\hline Public Management Department of Liuzhou Teachers & 6 & Guangxi \\
Zhejiang Financial College & 5 & Zhejiang \\
Institute of Vocational Education and Adult Education, & Shanghai \\
East China Normal University & 4 & Jilin \\
Research Center of Ideological and Political Education of & 3 & Guangdong \\
Northeast Normal University & 3 & Hebei \\
Guangzhou Railway Polytechnic & 3 & Hebei \\
Basic Department of Hebei Communications Vocational and & & Tianjin \\
Technical College & 3 & Tianjin \\
Tangshan vocational \& technical college & 3 & \\
School of Education, Tianjin University & 3 & \\
Tianjin University of Technology and Education & & \\
\hline
\end{tabular}

cooperation cooperation map of sample documents with "Institution" as the node (Figure 2). There are 614 nodes and 108 connections in the figure. The density is 0.0006 . Due to the low overall density, this paper will adjust the frequency by $\geq 2$ and make appropriate manual adjustments. The nodes in the figure represent research institutions, the size of the nodes represents the amount of documents, and the connections between nodes represent the inter-institutional cooperation. It can be seen from the figure that the Public Management Department of Liuzhou Teachers College is at the core of the map and has the largest node. In terms of institutional cooperation, there is less cooperation between organizations, and there is no cooperation relationship between research institutions with more than three times of publications, and there is sparse existence of two or two cooperation organizations with less than three publications.

Finally, through the statistics of the regions where the research institutions of the sample literature are located, it is known that these areas are mainly distributed in North China, Northeast China, East China, South China, including three 


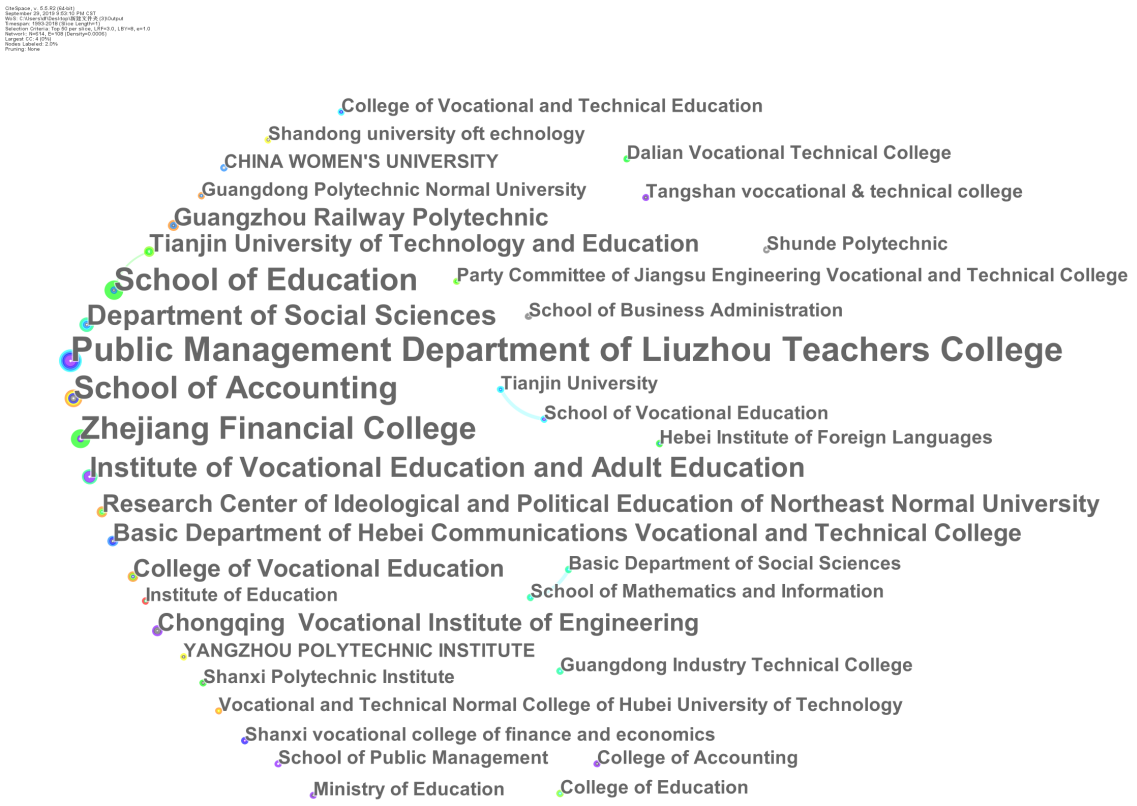

Figure 2. Knowledge map of cooperation among research institutions of professional ethics education.

municipalities directly under the Central Government of Shanghai, Chongqing, and Tianjin. The regional distribution of research power is relatively scattered. The research power of Guangxi in South China ranks first, and the economically developed research centers in Zhejiang and Shanghai are among the best. The spatial differences in research in this area also reflect the differences in attention to professional ethics education across regions.

To sum up, we can see that: 1) At present, there are many research institutions in this field, but there are still no influential institutions. The authoritative research institutions in this field need to be further explored. 2) The cooperation among institutions is weak, there are no research teams, and many research teams need to be formed in the future. 3) There are no provinces in the western region in the research field, indicating that the research forces in this field are not evenly distributed. More exchanges and cooperation should be carried out between different regions to promote the study of professional ethics education. The results have been further improved.

\subsection{Research Author Analysis}

The author's number of studies can measure the scale of research in this field (Yu, 2019). Figure 3 shows the collaborative knowledge map of authors in the field of professional ethics. There are 783 nodes and 322 links in the figure. The overall density is 0.0011 . The nodes represent the authors and the links represent the cooperative relationship between the authors. It can be seen from the figure that the research authors in this field have formed three cooperative teams of six people, represented by $\mathrm{Wu}$ Bin, Li Qiangxiang and Tian Lihua, one team of five people represented by Yan Huishen, 12 four people, 29 three-person cooperation 


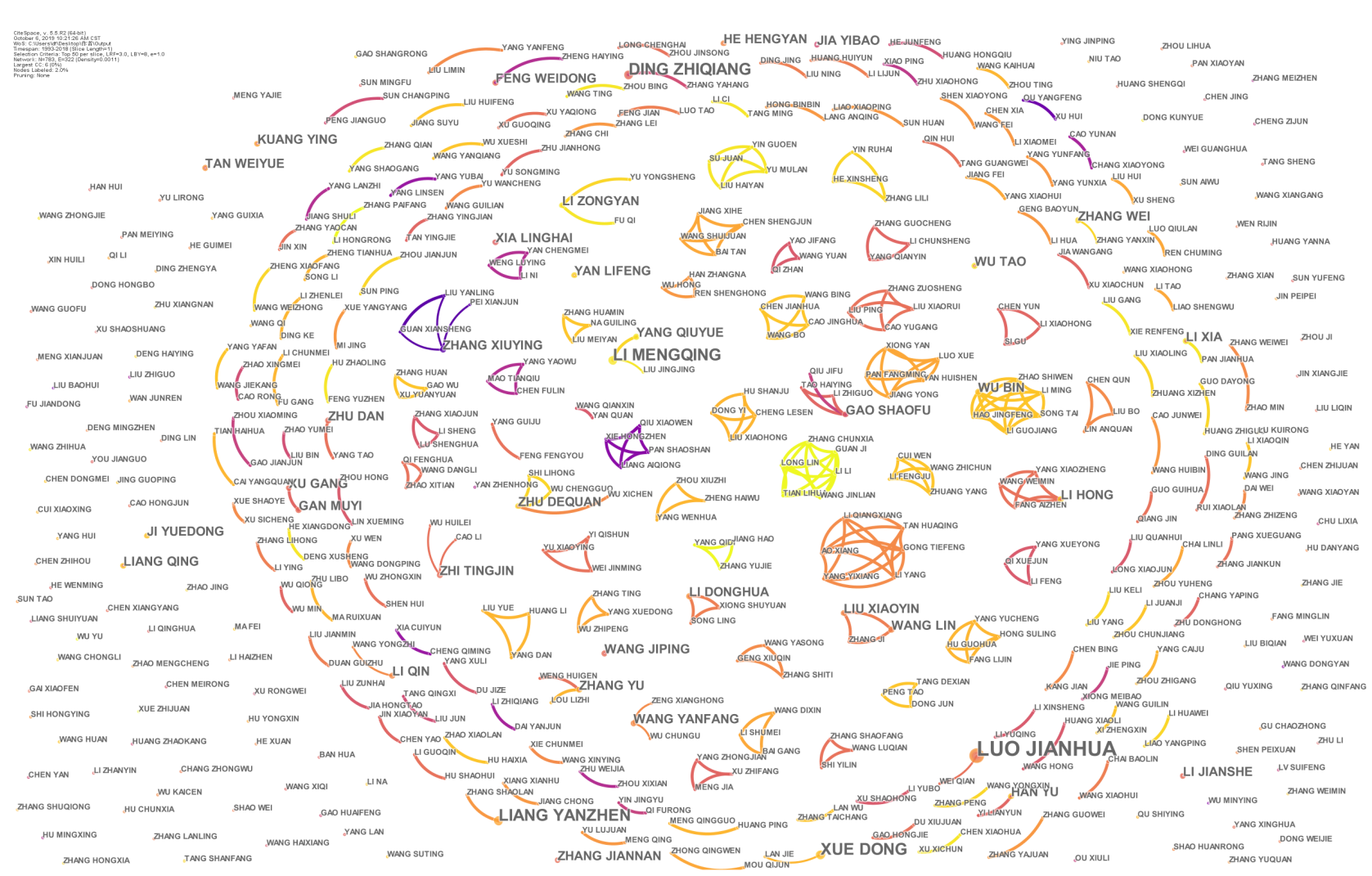

Figure 3. Cooperative network map of authors of professional ethics education research.

team and 115 two-two cooperation relationship. There are 388 authors who have a cooperative relationship, accounting for $49.55 \%$. It can be seen that the current research authors have formed a certain cooperative relationship, but there is still a considerable proportion of authors' cooperation. In the future, more influential cooperation teams will be formed to promote research in this field.

\section{Distribution of Research Contents and Analysis of Research Hotspots}

\subsection{Distribution of Research Content}

Through the statistics of highly cited papers on professional ethics education in core journals, the top five papers were cited (Table 3). The analysis of high-cited papers can understand the main content distribution of scholars in this field. The specific analysis is as follows:

The literature with the highest frequency of citations mainly analyzes the unsafe factors in nursing work and proposes corresponding management countermeasures. Yan, Weng \& Li (2003) believes that the unsafe factors in nursing work will directly affect the nursing effect, patient rehabilitation, the image of the hospital in the eyes of patients and the public, and has a negative impact on the reputation of the hospital. Even medical costs have risen, material consumption has increased, and the economic burden of patients has increased. In order to solve the problems in nursing, hospitals should improve the quality of nursing 
Table 3. Top 5 Certified professional ethics education research papers in core journals.

\begin{tabular}{lcccc}
\hline \multicolumn{1}{c}{ Title } & Author & Source & Citation times & Published year \\
\hline $\begin{array}{l}\text { Nursing unsafe factors analysis and Management } \\
\text { Countermeasures }\end{array}$ & $\begin{array}{c}\text { Yan Chengmei, } \\
\text { Weng Luying, Li Ni }\end{array}$ & Chinese Journal of Nursing & 388 & 2003 \\
$\begin{array}{l}\text { Study on the Coupling of Skilled Talents } \\
\text { Training and the Cultivation of Craftsman Spirit }\end{array}$ & Li Mengqing, Yang Qiuyue & Journal of Vocational Education & 153 & 2016 \\
$\begin{array}{l}\text { On the Connotation of Vocational Spirit in } \\
\begin{array}{l}\text { Higher Vocational Education Based on } \\
\text { Vocational Quality }\end{array}\end{array}$ & Sun Xiaoling & Journal of Vocational Education & 98 & 2012 \\
$\begin{array}{l}\text { Should Teachers Be Moralists? Philosophical } \\
\text { Reflection on Teachers' Morality }\end{array}$ & Gan Jianmei & Educational Research & and Experiment & 98 \\
$\begin{array}{l}\text { The Ways to Cultivate The Students' Professional } \\
\text { Ethics Should Be Perfected Increasingly }\end{array}$ & Cheng Zijun & Medicine \& Philosophy & 77 & 2003 \\
\hline
\end{tabular}

safety management, strengthen safety and quality education, improve nursing safety awareness, enhance legal concept, manage according to law, and pay attention to professional theory and technical operation training. Among them, in the management measures of strengthening safety quality education and raising awareness of nursing safety, it is pointed out that the study of rules and regulations should be combined with professional ethics education, and the basic requirements of nursing professional ethics are defined.

Li \& Yang (2016) mainly analyze the relationship between the cultivation of skilled talents and the cultivation of "artisan spirit", pointing out that the "artisan spirit" is an excellent gene for high-skilled talents. In the face of the imperfections of vocational education, it is necessary to strengthen the professional ethics education of students, so that the training of skilled talents can achieve the unity of high-level professional ability and good professional spirit.

Sun Xiaoling mainly systematically constructs the connotation of professional spirit based on professional quality. In the article, she pointed out that professional ethics is professional spirit. She believed that vocational spiritual education in higher vocational colleges is essentially professional spiritual education for students in Higher Vocational colleges. Professionalism is not only the spiritual temperament needed by modern industrial and commercial society, but also the spiritual temperament necessary for the self-development of professional people. It is related to the socialized large-scale production and the refinement of the division of labor.

Gan (2003) discussed the professional ethics of teachers and denied the view that "teachers should have the same high morality as moralists". He considered this to be a misunderstanding of the relationship between "teacher morality" and "educational morality". He believes that teachers' professional ethics and teachers' personal ethics are different. Teachers should have morality and they also need noble morality. However, this noble ethics is still an ordinary person's morality in essence, and teachers should not be regarded as moralists.

Cheng (2005) put forward the method of perfecting and perfecting the way of 
moral cultivation education for medical students in China by drawing lessons from the experience of foreign medical students' moral cultivation ways. He mentioned that it is necessary to combine professional ethics education with clinical medical practice to improve the self-moral education ability of medical students, and to find a way to cultivate medical students' professional ethics suitable for China.

It can be seen that the research contents in the field of professional ethics education are all around this theme, but they are relatively independent. They can be specifically analyzed for different occupations, and can also be constructed for the connotation of related nouns.

\subsection{Analysis of Research Hotspots}

The analysis of high-frequency word keywords in a time period can summarize the hot issues of scholars in this period. This paper uses Citespace to conduct a co-occurrence analysis of the keywords in the field of professional ethics education, and obtains the keyword co-occurrence map of Figure 4. A total of 80 keywords are selected and 161 lines are generated. The connection represents the total existence of the keywords. The overall density of the keywords in the map is 0.0509 .

According to Price's law, the core author's calculation formula is

$$
M_{a}=0.794 \sqrt{N_{\max }} .
$$

This formula also applies to the determination of high-frequency keywords (Wang \& Chen, 2014). $M_{a}$ is the high-frequency keyword threshold, and $N_{\max }$ is the highest value of the frequency of texts during the academic period. To ensure the scientific nature of the analysis, "professional ethics" is the word with the highest co-occurrence frequency except for the subject word "professional ethics

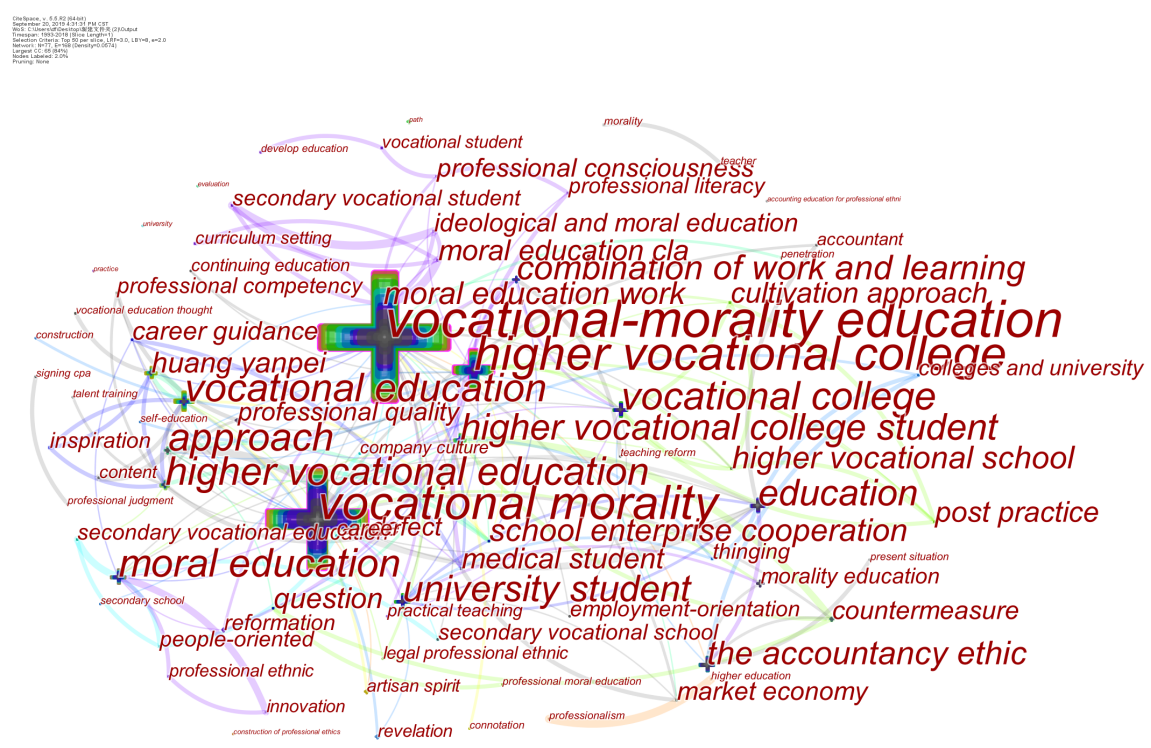

Figure 4. Professional ethics education research hotspot keyword co-occurrence map. 
education", and its frequency is 120 . The high-frequency keyword $M \approx 8.20$ in the field is calculated by Price's law. Therefore, the keywords with a frequency of not less than 9 are used as the high-frequency keywords studied in this paper. Since the centrality can reflect the importance of keywords in the co-occurrence map, it also measures the structure of the co-word network. Therefore, the specific frequency and centrality of high-frequency keywords are listed in the following table (Table 4), and combined with the status quo of research in the field of professional ethics education, the following important research hotspots are summarized.

First, the content of professional ethics education. This theme mainly includes high-frequency keywords such as "vocational morality", "vocational education", "the accountancy ethic", "education", "moral education", "morality education", "vocational college" and "higher vocational education". In the field of professional ethics education, the main content of scholars' research mainly focuses on moral education, education, vocational education and so on. General Secretary Xi (2012) pointed out: "We must adhere to the combination of ruling the country by law and ruling the country by virtue, and attach great importance to the normative role of morality in civic behavior." Scholars have studied the definition of this field and its existing problems.

With regard to the definition of related terms in this field, Gai (2009) pointed out that the vocational quality training of vocational college students mainly includes professional ethics, professional ability, professional personality, professional culture and other aspects. Professional ethics is the first priority in the cultivation of high-quality professionals. Ying (2009) and Tian (2007) all believe

Table 4. Professional ethics education research hot keywords.

\begin{tabular}{|c|c|c|c|}
\hline Keywords & Frequency & Centrality & Year \\
\hline vocational morality & 120 & 0.38 & 2000 \\
\hline higher vocational college & 58 & 0.35 & 2006 \\
\hline vocational education & 30 & 0.19 & 2006 \\
\hline the accountancy ethic & 24 & 0.07 & 2003 \\
\hline university student & 22 & 0.10 & 2007 \\
\hline education & 22 & 0.06 & 2000 \\
\hline higher vocational college students & 20 & 0.05 & 2009 \\
\hline moral education & 20 & 0.11 & 2003 \\
\hline Huang Yanpei & 18 & 0.04 & 2007 \\
\hline morality education & 14 & 0.00 & 2006 \\
\hline vocational college & 11 & 0.01 & 2008 \\
\hline combination of work and learning & 10 & 0.05 & 2008 \\
\hline higher vocational education & 10 & 0.07 & 2008 \\
\hline approaches & 10 & 0.09 & 2006 \\
\hline
\end{tabular}


that professional ethics is the ethical norms and guidelines that all practitioners should follow in the performance of their duties in professional activities. Zhu (2016) proposed that professional ethics education is an important part of higher vocational education, and it is also the main link to improve students' literacy and solve social moral education problems. Zhang \& Li (2018) also believe that professional ethics education is the righteousness of higher vocational colleges.

With regard to the problems in this field, Zhu Xiangnan, Zhang Paifang and Li Hongrong pointed out that in the process of professional ethics education in higher vocational colleges, there are some problems, such as weak pertinence of vocational ethics education, outdated methods of vocational ethics education, imperfect system of vocational ethics education, inadequate innovation of teaching contents and methods, and running schools with closed doors. As a result, the cultivation of professional ethics in the process of practice is neglected.

Second, the research object of professional ethics education. This theme mainly includes high-frequency keywords such as "higher vocational colleges", "university students", "higher vocational college students" and "Huang Yanpei". From the highly cited literature and the co-occurrence map, it is known that the research subjects in this field also include teachers, medical students, and accounting majors. $\mathrm{Wu}$ (2018) analyzed the origin, connotation and modern value of Huang Yanpei's vocational education teaching thoughts. And put forward the various measures of how to train students in vocational colleges in the new era. It can be seen that the famous educator Huang Yanpei has profound influence on modern vocational education in China. Regarding college students, General Secretary Xi Jinping pointed out when investigating China University of Political Science and Law: "Standing on the people of Lide, not only must improve the students' legal knowledge, but also cultivate students' ideological and moral qualities (People's Daily 2017)." Chen \& Xu (2017) also pointed out that strengthening the ideological and moral education of college students is always the fundamental starting point and foothold of building morality and cultivating people in Colleges and universities. Regarding teachers, the report of the 19th National Congress of the Communist Party of China clearly pointed out that it is necessary to "strengthen the construction of teachers' morality and ethics and cultivate a team of high-quality teachers." As for medical students, the Special Committee on International Medical Education stipulates in the Global Minimum Basic Requirements (GMER) of medical education that doctors trained in medical colleges all over the world must possess the basic qualities of "medical knowledge, clinical skills, professional attitude, behavior and professional ethics". Zhou \& Sun (2016) point out that while medicine contributes to society and serves people's health needs, the utilitarianism of medical behavior is increasingly revealed, and medical disputes and contradictions between doctors and patients are also increasing. Medical students' professional ethics and medical humanistic spirit are extremely important. As for higher vocational colleges and students, higher vocational colleges are the bases for training a large number of vocational talents, such as higher vocational students. Scholars mostly analyze 
the obligations of higher vocational colleges and the problems in vocational ethics education of higher vocational students. For example, Wang (2014) pointed out that some colleges lacked an operational evaluation mechanism for the specific behaviors and effects of higher vocational ethics education, which made the vocational colleges lack the motivation to invest in professional ethics education.

Third, the practical methods of professional ethics education. This theme mainly includes high-frequency keywords such as "combination of work and learning" and "approaches". On the basis of some scholars' proposals on professional ethics, many scholars have put forward specific methods and paths on how to carry out professional ethics education. Ying Jinping proposed that the exploration and practice of students' professional ethics training mechanism under the combination of work and study is the embodiment of the characteristics and quality of higher vocational talents. In the combination of engineering and learning, students have four identities at the same time. This makes professional ethics education not an isolated education, but a moral education system that combines personal morality, professional ethics, family virtues and social morality, which is conducive to the full development of students' professional ethics. Xu (2007) explored the ways of college students' professional ethics education from five aspects: classroom teaching, routine education activities, social professional practice experience, career design and implementation, corporate culture and campus culture. Liu, Huang \& Yang (2014) deconstructed the competency of accountants and proposed that integrating on-site learning and formal education is the core of professional ethics education. We should achieve the goal of increasing professional ethics sensitivity, fostering professional responsibility and improving professional ethics decision-making skills through all possible means.

\section{Research Trend}

Based on the co-occurrence of keywords, this paper selects "Timezone" in Citespace software and removes the keyword "professional moral education" to obtain the timezone of keywords in professional ethics education research (Figure 5). The larger the node in the figure, the more frequent the keyword appears, such as "vocational morality", "higher vocational colleges", "moral education", "university students", " approaches" and so on. From the time point of view, the time-series map of the professional moral education research in 1993-2018 can be divided into three time periods: the first stage from 1993 to 2003, the second stage from 2004 to 2009, and the third stage from 2010 to 2018 .

1993-2018 is the embryonic stage of research. There are few research literatures, and the keywords obtained are relatively limited, but they are more obvious in the map, such as "education", "vocational morality", "moral education" and other keywords. Liu (1998) put forward that professional ethics is an important part of Ideological and moral quality, and plays an important role in promoting the formation of professional quality. Chen (2003) pointed out that 


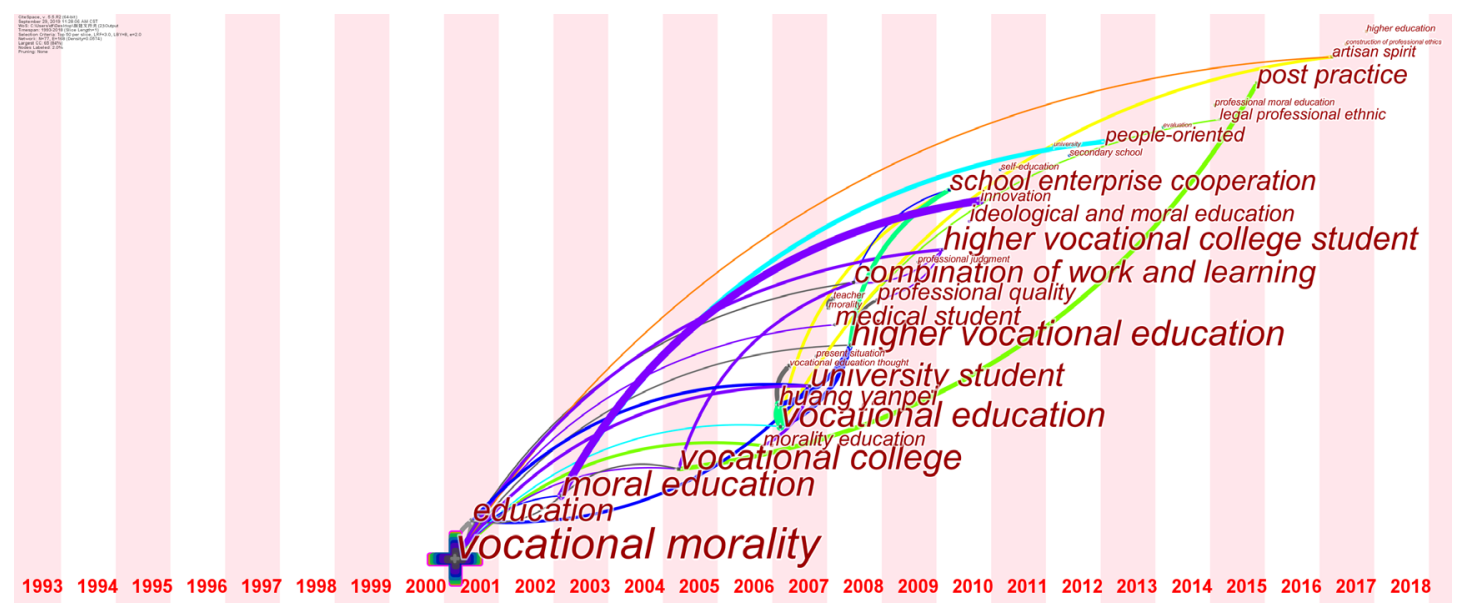

Figure 5. The timezone of keywords in professional ethics education research.

the focus of the prevention of professional morality is to strengthen the ideological and moral education in the article of strengthening the ideological and moral education in the construction of professional ethics. But at this time, the study of professional ethics education is mainly a brief discussion of the professional ethics phenomenon at this stage and a preliminary understanding of related concepts, which laid a foundation for the follow-up scholars to conduct in-depth research in this field.

2004-2009 is the rapid development stage of research. The emergence of keyword spurious in this stage, scholars in this field of research is more detailed. From the keywords of "medical students", "university students", "higher vocational college students", "teachers" and other key words, we can know that the research in this field from meticulous to precise occupation. At the same time, the "present situation", "vocational education thought", "morality education" "professional quality" has been deeply explored. The Ministry of Education and other seven departments "Several Opinions on Further Strengthening Vocational Education" (Faculty [2004] No. 12) pointed out that vocational colleges should fully implement quality education and strengthen the ideological and moral construction of students. Yin \& Qi (2005) pointed out that vocational quality education includes professional ethics education, professional knowledge quality education, professional physical and mental quality education, professional aesthetic quality education, vocational labor quality education. And they believed that vocational quality education in higher vocational colleges in China The core issue is the education and training of students' professional ethics.

2010-2018 is the slow development stage of research. "Several Opinions of the Ministry of Education on Promoting the Reform and Innovation of Higher Vocational Education Leading the Scientific Development of Vocational Education" (Faculty [2011] No. 12) emphasizes: "Insist on educating people first and moral education first. Higher vocational schools should integrate the socialist core value system and the excellent cultural concept of modern enterprises into the whole process of personnel training, and strengthen the cultivation of stu- 
dents' professional ethics and spirit." Yu (2018) pointed out that "patriotism, dedication, integrity and friendliness" are the corresponding moral requirements at the individual level between professional ethics and socialist core values, and the integration of socialist core values into professional ethics quality education is the internal requirement for the implementation of socialist core values. On the basis of the previous research results, the scholars at this stage have discussed the specific professional ethics such as "legal professional ethics" and "teacher professional ethics". At the same time, they analyzed the problems existing in the current professional ethics education, and put forward corresponding countermeasures, such as "craftsman spirit", "evaluation", "self-education", "school-enterprise cooperation" and so on. Niu (2014) puts forward that the professional ethics education of vocational college students is a process of multi-subject interaction and cooperation. The ways to realize it include classroom teaching of vocational ethics education, infiltration of relevant educational contents in daily practice activities, relevant contents in professional courses teaching, campus culture construction and education related to school-enterprise cooperation.

In summary, it can be seen that the research in the field of professional ethics education has been paid attention to in-depth and detailed discussion of the moral education and existing problems of different occupations, and then to think deeply about how to practice professional ethics education. At the same time, it can be found that the research in this field is closely related to the policy opinions of the relevant departments of the Ministry of Education. In 2016, Premier Li Keqiang proposed in the government work report that "cultivating the spirit of craftsmanship for excellence". In the same year, Li Mengqing and Yang Qiuyue, Zhou Jianjun and Sun Ping studied the combination of craftsman spirit and different talent training. The research in this field will always be guided by policies, and constantly find the problems in professional ethics education and find the mechanism to solve them.

\section{Conclusion}

Based on the bibliometric perspective, this paper makes a visual analysis of 596 articles on the subject of professional ethics education collected by core journals in CNKI database from 1993 to 2018 with Citespace and other software. It mainly analyses the current situation, content, hotspots and trends of the research in the field of professional ethics education, and draws the following conclusions.

Through the analysis of the authors, research institutions and the amount of papers in different fields in the field of professional ethics education, it is found that the field has experienced three stages of research sprouting, rapid development and slow development. At the same time, a large number of research scholars and research institutions have emerged, but the influential authors' cooperation team has yet to be explored, and the cooperation between research institutions needs to be strengthened. 
Through the analysis of the highly cited literature, the research content in this field mainly focuses on the theme of professional ethics education, and analyzes the ethical problems and solutions in different occupations and occupations. Through the analysis of the frequency of keywords and the co-occurrence map, the hot issues in the field are derived from three aspects. Firstly, the content of professional ethics education mainly includes the connotation determination of the related terms of professional ethics education and the existing problems in this field. Secondly, the research objects of vocational ethics education mainly focus on students, such as higher vocational students, medical students, college students, etc. At the same time, it also includes some professions which are widely concerned by the society, such as accounting, nursing, and cultivating the main body of Higher Vocational students, such as higher vocational colleges, which are also the hot research objects in this field.

Through the analysis of the keyword co-occurrence time zone map, it is found that the research in this field will always be policy-oriented, and the research of professional ethics will be extended to analyze the moral status of different occupations, so as to propose improvements to the existing problems. The countermeasures continue to improve the professional ethics education in China.

\section{Acknowledgements}

This research is financially supported by the Research and Planning Fund for Social Science Foundation of Jiangxi (18GL09), and Humanities and Social Sciences of Jiangxi education (GL18125), and Research of teaching reform in universities in Jiangxi Province (JXJG-18-2-42).

\section{Conflicts of Interest}

The authors declare no conflicts of interest regarding the publication of this paper.

\section{References}

Chen, B. L. (2003). The Focus of Professional Ethics Construction Is to Strengthen Ideological and Moral Education. Truth Seeking, S2, 174-175.

Chen, X. H., \& Xu, X. C. (2017). Subject Participation: Paradigm Choice of Innovation in College Students' Professional Ethics Education. Journal of Vocational Education, 32, $18-21$.

Cheng, Z. J. (2005). The Ways to Cultivate the Students' Professional Ethics Should Be Perfected Increasingly. Medicine \& Philosophy, 11, 78-79.

Gai, X. F. (2009). Essentials and Path Selection of Vocational Quality Training for Higher Vocational College Students. China Higher Education Research, No. 8, 82-83.

Gan, J. M. (2003). Should Teachers Be Moralists? Philosophical Reflection on Teachers' Morality. Educational Research and Experiment, No. 3, 25-30.

General Secretary Xi Jinping's Important Speech during His Visit to China University of Political Science and Law Aroused a Warm Response. People's Daily, 2017-05-04.

Li, M. Q., \& Yang, Q. Y. (2016). Study on the Coupling of Skilled Talents Training and 
the Cultivation of Craftsman Spirit. Journal of Vocational Education, 16, 21-26.

Liu, Y., Huang, L., \& Yang, D. (2014). Accounting Competency Deconstruction and Professional Accountancy Training-Analysis Based on International Education Standard. Accounting Research, No. 5, 29-36+94.

Liu, Z. M. (1998). Vocational Moral Education and the Formation of Professional Quality. Vocational and Technical Education, No. 5, 50-51.

Niu, T. (2014). Construction of a Comprehensive Quantitative Evaluation System for Vocational Ethics Education of Higher Vocational Students. Education and Vocation, 29, 63-65.

Sun, X. L. (2012). On the Connotation of Vocational Spirit in Higher Vocational Education Based on Vocational Quality. Journal of Vocational Education, No. 6, 62-65.

Tian, X. H. (2007). Problems and Countermeasures of College Students' Professional Ethics Education. China Adult Education, No. 2, 37-38.

Wang, H. (2017). Analysis on the Necessity of Strengthening Professional Ethics Education in Medical Vocational Colleges. Science \& Technology Information, 31, 171-172.

Wang, L. Y. (2014). Evaluation Mechanism of Higher Vocational College Student's Vocational Moral Education. Modern Education Management, 10, 110-113.

Wang, Y. M., \& Chen, H. B. (2014). Focus and Direction of e-Schoolbag Research in China in Recent Ten Years-Based on the Knowledge Map Analysis of Co-Word Matrix. China Educational Technology, No. 5, 4-10.

Wu, X. F., \& Liu, H. Y. (2017). Analysis of the Current Situation of Vocational College Students' Professional Ethics Education-Centered on the Pearl River Delta Region. China Economist, 12, 193-194.

Wu, Y. (2018). The Origin, Connotation and Modern Value of Huang Yanpei's Vocational Education Teaching Thought. Vocational and Technical Education, 39, 56-60.

Xi, J. P. (2012). Speech at the Congress Commemorating the 30th Anniversary of the Promulgation and Implementation of the Current Constitution in All Walks of Life in the Capital. People's Daily, (002).

Xiao, P., \& Zhu, X. H. (2004). The Current Situation of Professional Ethics and the Marginalization of Professional Ethics Education. Research in Higher Education of Engineering, No. 5, 40-43.

$\mathrm{Xu}$, S. Q. (2007). Strengthen Employment-Oriented College Students' Professional Ethics Education. Jiangsu Higher Education, 2, 103-105.

Yan, C. M., Weng, L. Y., \& Li, N. (2003). Nursing Unsafe Factors Analysis and Management Countermeasures. Chinese Journal of Nursing, No. 7, 55-57.

Yin, J. Y., \& Qi, F. R. (2005). Research on Quality Education in Higher Vocational Colleges. China Higher Education Research, 11, 61-62.

Ying, J. P. (2009). Thoughts on the Training Mechanism of Vocational Ethics for Higher Vocational Students under the Mode of Combining Work with Learning. Journal of Vocational Education, No. 9, 50-53.

$\mathrm{Yu}$, B. (2019). Visualization Analysis and Comparative Study of Knowledge Economy Situation in the Field of Library and Information Science at Domestic and Abroad. Information Science, 37, 150-156.

Yu, L. L. (2018). Analysis on the Training Path of Vocational Students' Professional Ethics Quality. Journal of Harbin Vocational \& Technical College, No. 2, 40-42.

Zhang, P. F., \& Li, H. R. (2018). Analysis on the Path of Vocational Ethics Education in Higher Vocational Colleges. Jiangsu Higher Education, 11, 105-108. 
Zhou, J. J., \& Sun, P. (2016). “Craftsman Spirit”: Cultivating Medical Students' Humanistic Quality and Professional Ethics Education. Chinese Vocational and Technical Education, 20, 42-44.

Zhu, X. N. (2016). Implication and Realization Path of Professional Ethics Education in Higher Vocational Colleges. Education and Vocation, 16, 57-59. 